\title{
Food Quality and Nutritional Status of Vegetarians in Two Main Cities of a Sub-Saharan Country
}

\author{
Azandjeme Colette Sylvie. ${ }^{1, *}$, Sossa Jerome Charles ${ }^{1}$, Sopoh Ghislain ${ }^{1}$, Ahanhanzo-Glele Yolaine ${ }^{1}$, \\ Degbegni Hermance ${ }^{2}$, Paraiso Noel. Moussiliou ${ }^{1}$, Metonnou Clémence ${ }^{1}$, Agueh Victoire ${ }^{1}$, \\ Ouendo Edgard-Marius ${ }^{1}$
}

\author{
${ }^{1}$ Department of Health Promotion, Public Health Regional Institute, PO Box 384, Ouidah, Benin \\ ${ }^{2}$ Department of Medicine and Specialties, Faculty of Health Science, University of Abomey-Calavi, PO Box 188, Cotonou, Bénin
}

Received February 6, 2020 ; Revised May 21, 2020; Accepted June 6, 2020

Copyright $\bigcirc 2020$ by authors, all rights reserved. Authors agree that this article remains permanently open access under the terms of the Creative Commons Attribution License 4.0 International License

\begin{abstract}
The objective of this research is to study the nutritional status and the diet quality of vegetarians in two main cities of Benin, Cotonou and Porto-Novo in order to contribute to the improvement of their diet. Data were collected from 101 vegetarians selected by commodity in vegetarian restaurants. BMI, waist circumference, energy intake from macronutrient, micronutrient intakes, alcohol consumption, physical activity level, and blood levels of iron, calcium and albumin are the main variables. Analyses were set using SPSS and ALIMENTHEQUE software. Associations were tested using Fisher and Chi square tests. Inadequate nutritional status is obesity $(6.93 \%)$, overweight $(26.73 \%)$ and under nutrition $(4.95 \%)$. People with a low daily fiber intake was higher among those with a BMI greater than 25 compared to those with a BMI less than $25(82.3 \%$ vs $61.1 \%$ with $p=0.03)$. As the diet becomes stricter, the prevalence of people with low daily vitamin B12 intakes significantly increases: presco/semi-vegetarians $(8.23 \%)$, lacto-vegetarians (27.05\%), vegans (52.94\%) ovo-lacto-vegetarians (3.8\%) $\mathrm{p}=0.04$. In general, a lack of balance in macronutrient intake (only $18.81 \%$ of normal carbohydrate, fat and protein intake) was noted, leading to problems of obesity (abdominal obesity $=23.7 \%$ Micronutrient intakes were low for the majority of subjects (vitamin $\mathrm{B} 12=84.16 \%$, zinc $=73.27 \%$, calcium $=65.35 \%$ ) except for iron $(32.6 \%)$, with normal serum levels except for iron (deficiency=19.5\%). Fiber intakes were also low for the majority $(68.3 \%)$, which has a negative effect on BMI and therefore on nutritional status. The vegetarian diet in this context is therefore related to nutritional problems.
\end{abstract}

Keywords Nutritional Status, Food Quality, Vegetarian, Cotonou, Porto-Novo

\section{Introduction}

In order to solve the problems of their time, human beings choose diets according to their religion, their environment and their beliefs. Vegetarianism is one of these and people who follow this diet are called vegetarians. These people have a strong attraction to the plant kingdom and consume only a certain variety of foods of animal origin.

Several studies suggest that a vegetarian diet would have a beneficial effect on health and life expectancy. For example, case-control studies show an association between the consumption of the vegetarian diet model and a reduced prevalence of the risk of developing a metabolic syndrome and cardiovascular diseases [1]. Furthermore, regardless of age, gender or country of origin, vegetarians are slimmer than omnivores and have a lower prevalence (less than 6\%) of obesity [2]. These benefits would be related to reduced consumption of potentially harmful dietary components such as saturated fat, cholesterol, animal protein, red meat, anthemion, and increased consumption of beneficial dietary components such as fruits, vegetables, whole grains, legumes rich in dietary fiber and antioxidants [3]. However, some studies show that these benefits are less significant when compared to healthy omnivorous diets. Vegetarianism would then be associated in some people with a deleterious nutritional state with weight loss and/or deficiencies in micronutrients such as vitamin B12 (in vegetarians who rarely take supplements or foods fortified with vitamin B12), iron, zinc, calcium and protein [4]. Furthermore, it has not yet been shown that it is the omission of meat per se that causes the positive effects of the diet, since vegetarians have a healthy lifestyle that includes the omission of harmful practices, particularly smoking and alcohol consumption. These non-dietary factors may also contribute to the effectiveness of the 
vegetarian diet [5].

The vegetarian diet is therefore the subject of several scientific studies and mobilizes divergent opinions regarding its impact on nutritional status in several countries, especially those in the West. But all this information on vegetarianism is almost absent when we look at the African continent. This is the main reason for conducting this study on vegetarianism in Benin, particularly in the country's major cities. It is essentially based on the following research question: "Is the vegetarian diet led in Benin harmful or favorable for the adherents of this dietary practice? "».

\section{Materials and Methods}

\subsection{Study Population}

The study population includes all persons over fifteen (15) years old living in Cotonou or Porto-Novo who have adopted a vegetarian diet and who will be attending vegetarian restaurants in the two cities in 2015.

\subsection{Inclusion and Exclusion Criteria}

All vegetarians 15 years of age and older who attended the targeted restaurants during the study period were included provided they gave written informed consent. During the study, he was considered a vegetarian, anyone who eliminated meat, fish and poultry from their usual diet. However, we have distinguished between veganism (single consumption of foods of plant origin), semi-vegetarianism (transitional form between vegetarianism and meat consumption), ovo-lacto-vegetarianism (inclusion of eggs, milk and honey in the diet), lacto-vegetarianism (consumption of milk, (excluding all animal and dairy products but including eggs), ovo-vegetarianism (excluding all animal and dairy products but including eggs), presco-vegetarianism (including fish in the diet) and vitarian (consuming only organic products and fresh or raw food). People who went to vegetarian restaurant occasionally and those who were fasting were excluded.

\section{Sampling}

Since we did not have a list of all vegetarians in the two cities, we conducted non-probability sampling for convenience to include 101 people in the study paragraph. Do not add any kind of pagination anywhere in the paper. Do not number text heads - the template will do that for you. Finally, complete content and organizational editing before formatting. Please take note of the following items when proofreading spelling and grammar.

\subsection{Definition of the Variables under Study}

To appreciate the Body Mass Index (BMI) we have considered the following classes at savoir $<18,5$, between 18.5 and 25,25 and 30,30 and 35,35 and 40 and finally greater than or equal to 40 . Waist circumference was assessed by considering a standard of $94 \mathrm{~cm}$ for men and 80 $\mathrm{cm}$ for women [6] The frequency of food consumption over two months, dietary diversity, the number of fruits and vegetables consumed per day, energy intake and some nutrients, namely vitamin $\mathrm{B} 12$, iron and calcium, were assessed based on the nutrient intakes recommended by Health Canada [6] and the European Food Safety Authority (EFSA) [7]. Energy requirements were assessed by taking into account physical activity level, weight, height and age [6]. The norm for alcohol consumption was one standard drink per day for women and two drinks for men [8]. Blood levels of iron, calcium and albumin were assessed by sampling and laboratory analysis.

\subsection{Questionnaires}

To collect data from study participants, we used a questionnaire on socio-demographic factors (age, gender, marital status, occupation, religion), a questionnaire on vegetarianism profiles, and a frequency/diversity score questionnaire to qualitatively assess usual consumption of certain food groups and dietary diversity [9], a 24-hour dietary recall to provide information on food consumption and a questionnaire to evaluate the level of physical activity that codes from 1 to 5 the duration of sedentary activities as well as leisure and work-related physical activities [10].

\subsection{Ethical Considerations}

Data were collected from vegetarians after obtaining their free and informed consent to participate in the study. Anonymity and confidentiality have been respected when processing the data. A debriefing session was held for participants at the end of the study.

\subsection{Statistical Analysis}

The food data were entered using the ALIMENTEQUE software in its version 3.5. This software allowed us to assess macronutrient and micronutrient intakes. The remaining data were entered and analyzed using STATA software. Pearson's Chi ${ }^{2}$ de Pearson test and Fischer's test were used to look for associations between the different variables in the study. The significance level for the tests was $5 \%$.

\section{Results}

Of the 101 participants, $88(87.13 \%)$ were male and 13 $(12.87 \%)$ were female. The majority of them were married $(66 \%)$ and the rest were single (34\%), and their occupations were, in order of importance, middle 
management (45.16\%), employees $(19.3 \%)$, senior management (18.2\%) and craftsmen, tradesmen and workers $(16 \%)$. The main religion adopted was the exoteric one (spirituality) with $41 \%$ followed by Christianity (33.6\%) and Atheism (14.8\%). 30.69\% of the participants were sedentary and $69.31 \%$ were active. $79.21 \%$ of them did not consume alcohol and $20.79 \%$ who did, including 2 people with harmful consumption.

\subsection{Food Quality}

As shown in Table 1, the food consumption of the subjects was consistent with the previous definition of vegetarianism when looking mainly at the proportions of fruit and vegetable consumption $(82.08 \%$ daily consumption) and red and white meat consumption (consumption respectively absent in $91.08 \%$ and $87.1 \%$ and rare in $2.9 \%$ and $4.9 \%$ ).

Table 1. Distribution of Subjects by Frequency of Food Consumption ( $\mathrm{n}=101)$.

\begin{tabular}{|c|c|c|c|c|c|c|}
\hline \multirow[b]{2}{*}{ Food Groups } & \multicolumn{6}{|c|}{ n(\%) } \\
\hline & $\begin{array}{l}\text { Very } \\
\text { Often }\end{array}$ & Often & $\begin{array}{l}\text { Very } \\
\text { Often }\end{array}$ & Rarely & $\begin{array}{l}\text { Very } \\
\text { Often }\end{array}$ & Never \\
\hline Eggs and egg products & $0(0,00)$ & $7(06,93)$ & $7(06,93)$ & $3(02,97)$ & $4(03,96)$ & $80(79,20)$ \\
\hline Milk and dairy products & $5(04,95)$ & $19(18,81)$ & $14(13,86)$ & $6(05,94)$ & $6(05,94)$ & $51(50,49)$ \\
\hline Sweet drinks and fruit juices & $15(14,85)$ & $38(37,62)$ & $19(18,81)$ & $12(11,88)$ & $4(3,96)$ & $13(12,87)$ \\
\hline Alcoholic Beverages & $3(02,97)$ & $3(02,97)$ & $9(08,91)$ & $7(6,93)$ & $9(08,91)$ & $70(69,30)$ \\
\hline Fast Food & $3(02,97)$ & $11(10,89)$ & $6(05,94)$ & $10(09,90)$ & $17(16,83)$ & $54(53,46)$ \\
\hline Fruits & $60(50,40)$ & $32(31,68)$ & $8(07,92)$ & $1(0,99)$ & $0(0,00)$ & $0(0,00)$ \\
\hline Infusions & $14(13,86)$ & $15(14,85)$ & $23(22,77)$ & $13(12,87)$ & $9(08,91)$ & $27(26,73)$ \\
\hline Exciting drinks & $16(15,84)$ & $22(21,78)$ & $15(14,85)$ & $7(06,93)$ & $21(20,79)$ & $20(19,80)$ \\
\hline Guillotines & $13(12,87)$ & $20(19,80)$ & $21(20,79)$ & $16(15,84)$ & $15(14,85)$ & $16(15,84)$ \\
\hline
\end{tabular}

Table 2. Distribution of subjects according to the number of servings of fruits and vegetables consumed per day, dietary diversity and energy intake $(\mathrm{n}=101)$.

\begin{tabular}{|c|c|c|}
\hline & $\mathbf{N}$ & $(\%)$ \\
\hline \multicolumn{3}{|c|}{ Fruit and vegetables per day } \\
\hline Less than 5 & 63 & 62,38 \\
\hline 5 and more & 38 & 37,62 \\
\hline \multicolumn{3}{|l|}{ Diversity Score } \\
\hline Average (4-5) & 1 & 0,99 \\
\hline Diversified (5-14) & 100 & 99 \\
\hline \multicolumn{3}{|l|}{ Total energy inputs } \\
\hline Low & 67 & 66,34 \\
\hline High & 34 & 33,66 \\
\hline \multicolumn{3}{|l|}{ Protein } \\
\hline Low & 35 & 34,65 \\
\hline Normal & 63 & 62,38 \\
\hline High & 3 & 02,97 \\
\hline \multicolumn{3}{|l|}{ Carbohydrates } \\
\hline Low & 7 & 06,93 \\
\hline Normal & 39 & 38,61 \\
\hline High & 55 & 54,46 \\
\hline \multicolumn{3}{|l|}{ Lipids } \\
\hline Low & 49 & 48,51 \\
\hline Normal & 40 & 39,60 \\
\hline High & 12 & 11,88 \\
\hline
\end{tabular}


Table 2 shows that only $37.6 \%$ of the participants complied with the recommendations for fruit and vegetable consumption. With the exception of one participant who had a moderately diversified diet, all other subjects had a diversified diet. One third of the vegetarians surveyed $(34.6 \%)$ had low daily protein intakes and $2.9 \%$ had high intakes. More than half of the participants $(54.6 \%)$ had high carbohydrate intakes. For fat, $48.5 \%$ had low intakes and $11.88 \%$ had high intakes. Only $18.81 \%$ of participants (19 people) had normal intakes of carbohydrate, fat and protein.

Table 3 shows that $68.3 \%$ of the participants had low daily fiber intakes.

Their daily intakes of vitamin B12, calcium and zinc were low for the majority of subjects in the sample, i.e. $84.16 \%, 65.35 \%$ and $73.27 \%$ respectively. Dietary iron intake was low for more than a third of the subjects (32.6\%).

Table 3. Distribution of subjects according to daily fiber and micronutrient intakes $(\mathrm{n}=101)$.

\begin{tabular}{|c|c|c|}
\hline Variables & Staff & $\%$ \\
\hline \multicolumn{3}{|l|}{ Fiber } \\
\hline Low & 69 & 68,32 \\
\hline Normal & 32 & 31,68 \\
\hline \multicolumn{3}{|l|}{ Vitamin B12 } \\
\hline Low & 85 & 84,16 \\
\hline Normal & 16 & 15,84 \\
\hline \multicolumn{3}{|l|}{ Calcium } \\
\hline Low & 66 & 65,35 \\
\hline Normal & 35 & 34,65 \\
\hline \multicolumn{3}{|l|}{ Iron } \\
\hline Low & 33 & 32,67 \\
\hline Normal & 68 & 67,33 \\
\hline \multicolumn{3}{|l|}{ Zinc } \\
\hline Low & 74 & 73,27 \\
\hline Normal & 27 & 26,73 \\
\hline
\end{tabular}

\subsection{Nutritional Status}

As shown in Table 4, $23.7 \%$ of the participants were abdominal obese with respect to waist circumference, while $61.3 \%$ had a BMI of $6.93 \%$ obese and $4.95 \%$ malnourished. No protein (serum albumin) deficiency was observed among the participants. However, $19.5 \%$ of the subjects were deficient in iron and $2.4 \%$ in calcium (one person).
Table 4. Distribution of vegetarians according to waist circumference, BMI and serum iron, albumin and calcium levels $(n=101)$.

\begin{tabular}{|c|c|c|}
\hline & $\mathbf{N}$ & $\%$ \\
\hline \multicolumn{3}{|c|}{ Waist circumference } \\
\hline High & 24 & 23,76 \\
\hline Normal & 77 & 76,24 \\
\hline \multicolumn{3}{|l|}{ BMI } \\
\hline$<18,5$ & 5 & 04,95 \\
\hline $18,5-24,9$ & 62 & 61,39 \\
\hline $25-29,9$ & 27 & 26,73 \\
\hline$\geq 39$ & 7 & 06,93 \\
\hline \multicolumn{3}{|l|}{ Serum iron } \\
\hline Low & 8 & 19,51 \\
\hline Normal & 33 & 80,49 \\
\hline \multicolumn{3}{|l|}{ Calcium } \\
\hline Low & 1 & 02,44 \\
\hline Normal & 40 & 97,56 \\
\hline \multicolumn{3}{|c|}{ Serum albumin } \\
\hline Low & 0 & 0,00 \\
\hline Normal & 41 & 100,00 \\
\hline
\end{tabular}

\subsection{Relationship between Dietary Quality and Vegetarianism Profile}

From Table 5 it can be seen that with the exception of the ovo-lacto-vegetarian diet, as the diet became stricter, the prevalence of people with low daily intakes of vitamin B12 increased.

Table 5. Association between micronutrient intakes and vegetarianism profiles $(\mathrm{n}=101)$.

\begin{tabular}{|c|c|c|c|c|}
\hline & \multicolumn{4}{|c|}{$\mathrm{n}(\%)$} \\
\hline & $\begin{array}{c}\text { Lacto/ } \\
\text { Ovo-lacto }\end{array}$ & Vegan & $\begin{array}{c}\text { Semi/ } \\
\text { Presco }\end{array}$ & p-value \\
\hline $\begin{array}{c}\text { Vitamin } \\
\text { B12 }\end{array}$ & & & & $\mathbf{0 , 0 4}^{*}$ \\
\hline Low & $26(30,58)$ & $45(52,94)$ & $14(16,47)$ & \\
\hline Normal & $04(25,00)$ & $5(31,25)$ & $7(43,75)$ & \\
\hline Calcium & & & & $\mathbf{0 , 4 1 * *}$ \\
\hline Low & $19(28,28)$ & $35(53,03)$ & $12(18,18)$ & \\
\hline Normal & $11(31,42)$ & $15(42,85)$ & $09(25,71)$ & \\
\hline Iron & & & & $\mathbf{0 , 8 0 * *}$ \\
\hline Low & $09(27,27)$ & $17(51,51)$ & $07(21,21)$ & \\
\hline Normal & $21(30,88)$ & $33(48,52)$ & $14(20,58)$ & \\
\hline Zinc & & & & $\mathbf{0 , 8 0 * *}$ \\
\hline Low & $21(28,37)$ & $39(52,70)$ & $14(18,91)$ & \\
\hline Normal & $09(33,33)$ & $11(40,74)$ & $07(25,92)$ & \\
\hline
\end{tabular}

*Fisher's test, ${ }^{* *}$ Pearson's Chi square test 


\subsection{Relationship between Food Quality and Nutritional Status}

As shown in Table 6, when considering each vegan and other vegetarian we don't find any relation with BMI.

The proportion of people with a low daily fiber intake is significantly higher in people with a BMI of 25 and upper $(82.3 \%)$ than among those with a BMI less than 25 $(61.1 \%)$.

Table 6. Association between food intake and BMI $(n=101)$

\begin{tabular}{|c|c|c|c|c|c|}
\hline & \multicolumn{2}{|c|}{ BMI $<\mathbf{2 5}$} & \multicolumn{2}{c|}{ BMI $\geq \mathbf{2 5}$} & p-value \\
\hline & $\mathbf{N}$ & $\mathbf{\%}$ & $\mathbf{N}$ & $\mathbf{\%}$ & \\
\hline Vegetarian status & & & & & $0,89^{\text {a }}$ \\
\hline Vegan & 32 & 64,00 & 18 & 36,00 & \\
\hline Other vegetarian & 35 & 68,63 & 16 & 31,37 & \\
\hline Fiber intake & & & & & $0,03^{\text {b }}$ \\
\hline Low & 41 & 61,19 & 28 & 82,35 & \\
\hline Normal & 26 & 38,80 & 06 & 17,64 & \\
\hline
\end{tabular}

${ }^{\mathrm{a}}$ Fisher's test, ${ }^{\mathrm{b}}$ Pearson's Chi square test

\section{Discussion}

The distribution of vegetarian subjects in our study according to frequency of consumption allowed us to observe prevalence that are justified by Woo et al. who describe vegetarian eating habits as traditionally based on fruits, vegetables (all edible varieties), cereals, and legumes [1]. Indeed, we observed proportions of $82.08 \%$ and $87.12 \%$ in relation to regular consumption of fruits and vegetables and a proportion of $55.3 \%$ for the consumption of legumes. As for the daily consumption of eggs and milk, the proportions are 6.9 and $23.7 \%$. Also, $87.1 \%$ and $91.08 \%$ of the subjects never ate white meat and red meat respectively. Pilis et al. find the same observations as Woo et al. by defining vegetarianism as the elimination of meat, fish and poultry from food consumption and consumption based mainly on food products of plant origin $[1,5]$. Based on our assessment of fruit and vegetable consumption, the majority of our subjects had low daily fruit and vegetable intakes. This finding is contrary to the observations made by the researchers mentioned above. This could be related to Beninese eating habits in which vegetables and fruits are not preferred. The possible non-representativeness of our sample and the fact that we could not differentiate between fruit and vegetable consumption could also explain this difference. However, one important observation should be noted. All participants had a diversified diet even though the lowest scores we observed were found for the vegan profile. However, this good dietary diversification did not prevent the energy intakes of all participants from being either high or low, with a very large low tendency $(66.34 \%)$. The greatest low trends were observed in subjects who adopted the vegan and semi-vegan profiles.
Key et al. argue that the majority of vegetarians have low proportions of protein consumption [11]. Indeed, we observed that one third of the participants had low protein intakes but we also noted that $62.3 \%$ had normal intakes and even $2.9 \%$ had high intakes. During our survey, we noticed a high consumption of gluten skewers by the vegetarians who participated in our survey. Gluten, a very high source of protein, is often consumed as an aperitif before meals containing other protein sources and as a snack. However, an appreciation of gluten consumption was not expected. The carbohydrate intake of our subjects is largely high for more than half of them (55.4\%) and even higher among vegans. This finding is in line with that made in two other studies which support that the vegetarian diet is rich in carbohydrates with higher intakes among vegans $[11,12]$. As argued by Marsh et al. in their writings on the health implications of vegetarianism, vegetarians' dietary intakes are reduced in fat [3]. Indeed, $48.5 \%$ of participants had low fat intakes. Based on the frequency of food consumption, we observed that only $14.8 \%$ of the vegetarians in our study consumed oils and fats regularly. Nevertheless, $11.8 \%$ of them had high fat intakes. The risk of suffering from cardiovascular disease or other chronic diseases related to excess fat is therefore not to be neglected. Considering the recommendations for all macronutrients, we found that only $18.81 \%$ of the participants had adequate intakes. This low proportion of participants with adequate macronutrient intakes is worrisome and deserves urgent action for those who adopt this diet in order to avoid the occurrence of both nutritional problems of deficiency and overload with their corollary nutritional diseases.

All the vegetarians in the study had significantly low intakes of vitamin B12, zinc and copper as argued by Key et al [12]. We also found that $68.2 \%$ of them had low daily fiber intakes. These findings are not similar to those of Barnard et al. who suggest that a vegetarian diet should be very high in fiber [13]. Although the vegetarians in our study were vegans and preferred fruits and vegetables, their fiber intake was generally low. We have seen above that the majority of vegetarians in our study are vegans and prefer fruits and vegetables, but their fiber intake was generally low.

The results of this study could not be extrapolated to the whole city of Cotonou or Porto-Novo because the technique of selection of subjects does not allow to have an external validity since these subjects do not represent all vegetarians but only those who visit vegetarian restaurants.

\section{Conclusions}

The diet as adopted by the vegetarians surveyed poses problems of under nutrition, overweight and obesity. Nutritional education should be provided to those who 
adopt this diet in order to prevent the occurrence of nutritional problems in this population group.

\section{REFERENCES}

[1] Woo KS, Kwok TC, Celermajer DS. Vegan diet, subnormal vitamin B-12 status and cardiovascular health. Nutrients. 2014 Aug 19; 6(8):3259-73.

[2] Grant J-D. Matière à réflexion pour une bonne santé: Préconiser une alimentation à base de plantes.Can Fam Physician. 2012;58(9):e472-e474.

[3] Marsh K, Zeuschner C, Saunders A. et al. Health Implications of a Vegetarian Diet: A Review. Am J Lifestyle Med. 2012; 6(3):250-267.

[4] Sabaté J, Wien M. A perspective on vegetarian dietary patterns and risk of metabolic syndrome. Br J Nutr. 2015 Apr;113 Suppl 2:S136-43.

[5] Pilis W, Stec K, Zych M, Pilis A. Health benefits and risk associated with adopting a vegetarian diet. Rocz Panstw Zakl Hig 2014;65(1):9-14.

[6] Santé Canada. (page consulté le 09/08/2006). Apports nutritionnels de références, [en ligne]. http://www.sc-hc.gc.ca

[7] Scientific committee on Food. Tolerable upper intake levels for vitamins and minerals: scientific panel on dietetic products, nutrition and allergies; 2006. ISBN 92-9199-014-0. European Food Safety Authority.

[8] Organisation Mondiale de la Santé. Stratégie mondiale pour l'alimentation, l'exercice physique et la santé. Mai 2004. $24 \mathrm{p}$.

[9] Division de la nutrition et la protection des consommateurs de la FAO. Guide pour la mesure de la diversité alimentaire au niveau des individus et des ménages. $3^{\mathrm{eme}}$ éd. Rome; 2007. $22 \mathrm{p}$.

[10] Laureyns F, Sene JM. Questionnaire d'évaluation du niveau d'activité physique: Projet de mutualisation de l'activité physique en cancérologie; 2015. Réseau régional de cancérologie. $1 \mathrm{p}$.

[11] Key TJ, Appleby PN, Rosell MS. Health effects of vegetarian and vegan diets. Proc Nutr Soc. 2006 Feb;65(1):35-41.

[12] Barnard ND, Gloede L, Cohen J, Jenkins DJ, Turner-McGrievy G, Green AA, Ferdowsian H. A low-fat vegan diet elicits greater macronutrient changes, but is comparable in adherence and acceptability, compared with a more conventional diabetes diet among individual with type 2 diabetes. J Am Diet Assoc. 2009 Feb;109(2):263-72. 